\title{
Municipio inteligente por un desarrollo local sostenible desde la gestión del conocimiento
}

\author{
Município inteligente para o desenvolvimento local sustentável a partir da \\ gestão do conhecimento
}

\author{
Smart municipality for sustainable local development from knowledge \\ management
}

\author{
Alejandro Emilio Ramos Rodríguez ${ }^{1}$ \\ Elaine Artigas Pérez ${ }^{1}$ \\ Aimara Brito Montero ${ }^{1}$
}

\begin{abstract}
Resumen: En una sociedad basada en el conocimiento, la universidad se convierte en un elemento clave del sistema de innovación, como proveedora de talento humano y promotora de nuevas tecnologías. La universidad, como actor clave de conocimiento, forma nuevos profesionales a través de la diseminación, producción, generación y utilización del conocimiento. El conocimiento universitario está comprometido con el desarrollo en todas sus dimensiones, y ello con el propósito de avanzar hacia un modelo de desarrollo basado en el conocimiento, lo que es imprescindible en la consecución de Municipios Inteligentes por un desarrollo local que requiere de la activa participación de todos los actores sociales implicados en dichos procesos para la generación de conocimientos, en cada uno de los contextos de actuación.

Palabras clave: gestión del conocimiento; municipio inteligente; desarrollo local sostenible.

Resumo: Em uma sociedade baseada no conhecimento, a universidade se torna um elemento-chave do sistema de inovação, tanto como provedor de talentos humanos quanto como promotor de novas tecnologias. A universidade, como ator-chave do conhecimento, capacita novos profissionais por meio da disseminação, produção, geração e uso de conhecimento. O conhecimento universitário está comprometido com o desenvolvimento em todas as suas dimensões, e isso com o objetivo de avançar a um modelo de desenvolvimento baseado no conhecimento, o que é essencial para a concretização dos Municípios Inteligentes para um desenvolvimento local que exija a participação ativa de todos os atores sociais envolvidos nesses processos para a geração de conhecimento, em cada um dos contextos de ação.
\end{abstract}

Palavras-chave: gestão do conhecimento; município inteligente; desenvolvimento local sustentável.

Abstract: In a knowledge-based society, the university becomes a key element of the innovation system, both as a provider of human talent and as a promoter of new technologies. The university, as a key knowledge actor, trains new professionals through the dissemination, production, generation, and use of knowledge. The university knowledge is committed to development in all its dimensions, and this with the purpose to move towards a knowledge-based development model, which is essential in achieving Smart Municipalities for a local development that requires the active participation of all social actors involved in these processes for the generation of knowledge, in each of the contexts of action.

Keywords: knowledge management; smart municipality developing; sustainable local development.

\section{INTRODUCCIÓN}

La investigación se enfoca en la consecución de municipio inteligente por un desarrollo local teniendo como base la gestión del conocimiento. Tiene como objetivo revelar el trabajo desarrollado por el Centro de Estudios para la Gestión del Desarrollo (CEGED) de la Universidad Agraria de La Habana, a partir de la visión multidimensional del desarrollo - social, económica, política, cultural y ambiental -, de la gestión social del desarrollo y su construcción social. Este

\footnotetext{
${ }^{1}$ Universidad Agraria de la Habana, Habana, Cuba.
} 
modelo se gesta desde los proyectos de sistema de información y conocimientos para el desarrollo agrario y rural sostenible, y socialización de los procesos de innovación para el desarrollo municipal. La hoja de ruta de municipio inteligente, unido al enfoque de desarrollo humano, posibilitó una visión de desarrollo centrado en las capacidades, a partir de la integración que favorece la triple hélice social, bajo una visión transdisciplinar que rebasa las disciplinas de la academia hacia el gobierno y la comunidad.

Avanzar hacia modelos de desarrollo sostenibles en la consecución de Municipios Inteligentes por un desarrollo local requiere de la activa participación de todos los actores sociales implicados en dichos procesos, en cada uno de los diferentes contextos. Por ello, actualmente se reconoce que una organización que quiera ser competitiva en el futuro tendrá que contar con una estrategia que actúe en favor del entorno del que forma parte y en el que desarrolla su actividad, comprometiéndose de esta forma con los principios y/o postulados de lo que se conoce como Responsabilidad Social Universitaria (RSU).

EI CEGED visualiza su responsabilidad social como un instrumento para fortalecer la vinculación universidad-entorno social, a partir de la articulación de las funciones universitarias -formación, investigación y extensión-. En este marco, la promoción de la RSU como visión integradora de la universidad es un gran aporte a los desafíos de la educación superior en nuestro tiempo; y da sentido original de la universidad como motor y garante de los procesos de desarrollo municipal.

sEl conocimiento universitario está comprometido con el desarrollo en todas sus dimensiones y ello con el propósito de avanzar hacia un modelo de desarrollo basado en el conocimiento, lo que se ha dado en llamar "nuevo desarrollo" (AROCENA; SUTZ, 2003; 2015). El propósito no es potenciar la capacidad de conocimiento, sino que la construcción de conocimientos en las universidades debe generar desarrollo.

La gestión del conocimiento para el desarrollo es uno de los procesos más generales del Modelo Municipio Inteligente por un desarrollo sostenible. Dicha gestión se realiza en el contexto de actuación del municipio. El conocimiento es un producto social que reúne en sí muchas cualidades, pero él solo no puede crear riquezas, es preciso un sistema que lo gestione (CASTRO DÍAZ-BALART, 2006; CASTRO; SUTZ, 2010; PASSAILLAIGUE; ESTRADA, 2016).

El gran reto de la gestión del conocimiento es que el conocimiento propiamente dicho no se puede gestionar como tal; sólo es posible gestionar el proceso y el espacio para la creación de conocimiento. De acuerdo con (DE SOUSA, 2008; 2014; HERRERA; GUTIÉRREZ, 2011; LARREA, 2016) para la gestión del conocimiento la misión fundamental debe ser explotar y desarrollar los activos de conocimiento que posee la organización a fin de que ésta pueda llevar a cabo su misión estratégica.

Di-Doménico (2008), considera igualmente que el conocimiento no se puede gerencial, que lo que es posible es gestionar el proceso y el espacio de la creación de conocimiento. Este propone a cambio "gestionar por el conocimiento" que es un proceso complejo porque amerita que la teoría se articule sobre la práctica de cada organización en particular.

Garcés (2013), refiere que el conocimiento es algo personal que no puede transferirse. Lo que se cree que es transferible, el conocimiento objetivo, debe siempre ser construido por el oyente. El oyente comprende y el conocimiento objetivo aparece como construido, pero solamente si él está preparado para comprender. 
Desde esta óptica es más un proceso de aprendizaje que de gestión. El término gestión de conocimiento ha sido cuestionado, primero porque es un término que procede del ámbito empresarial, con la idea de administrar conocimiento como si se tratara de un recurso más en la organización, y segundo porque no todo tipo de conocimiento se puede gestionar. El conocimiento tácito es propio e interno a cada persona, es conocimiento personal no codificado y cuando se trata de conocimiento social se trata de una reestructuración intelectual colectiva, imposible de administrar. Se puede gestionar la expresión del conocimiento, pero no el proceso intelectual o el crecimiento del intelecto humano (CANTO; COSTAMAGNA; EIZAGIRRE; LARREA, 2018).

De Souza y Cheaz (2003) y Ramos et al. (2016) refieren que solamente datos e información pueden ser adquiridos, procesados, almacenados, vendidos, etc.; conocimiento no. Aun cuando alguien comparte lo que para él/ella es su conocimiento concerniente a algún tema o problema, esto llega a las contrapartes-individuos, equipos, grupos sociales-como datos e información, que necesitan ser mentalmente y/o socialmente (re)configurados, (re)combinados, o (re)ordenados en confrontación con el conocimiento anterior de estos actores, y sus valores actuales y propósitos/ compromisos futuros.

En el Modelo Municipio Inteligente por un Desarrollo Local se aborda la gestión del conocimiento desde su generación, visto como un proceso totalmente humano que parte de la interacción de ideas, de la discusión, de la reflexión, de la asimilación a las experiencias de vida y de la transformación de las realidades. Esta generación se percibe más en el sentido de construcción de conocimiento y no de creación, ya que los procesos intelectuales que dan lugar a nuevos conocimientos son en realidad procesos de construcción en los cuales el individuo reestructura no sólo los conocimientos previos, sino las propias categorías intelectuales con las cuales se representa el mundo (NÚÑEZ, 2010; DÍAZ-CANEL, 2012; RAMOS et al., 2016).

Por lo tanto, el conocimiento no se crea como si surgiera de la nada de manera espontánea-, sino que se construye. Por eso se ha insistido que al construir conocimiento el individuo se construye porque no sólo cambia su conocimiento viejo por conocimiento nuevo, cambian sus categorías intelectuales y con ello cambia él. La construcción del conocimiento implica la autoconstrucción del individuo. La gestión del conocimiento no es una herramienta infalible, ni absoluta (CHUA, 2009), solo es válida si se aplica en correspondencia con las condiciones específicas de cada lugar; pueden existir experiencias parecidas, pero cada una es particular e irrepetible.

Bajo estas concepciones, se puede provocar la ruptura sutil de la cotidianidad, al crear nuevos espacios de participación que enriquecen la vida espiritual de las personas involucradas y al trasladarse hacia los contextos sociales. Este puede ser un elemento estratégico que contribuya a la inclusión social, al fortalecimiento de la conciencia crítica, de la creatividad como hecho social y personal, y sobre todo, al diálogo entre saberes a partir de la cooperación entre diferentes actores locales implicados y la participación social (GARCÍA, 2011).

Esos elementos pueden fortalecer la condición humana y el espíritu comunitario en los procesos de desarrollo que se gestan en un municipio, y condicionan positivamente los procesos de innovación local. Asimismo, se fortalece la cohesión social al articular el talento innovador de las personas en beneficio del desarrollo de su territorio porque es susceptible de ser dirigida hacia la promoción de competencias transformadoras del entorno social y cultural para elevar integralmente la calidad de vida de manera sostenible (COSTAMAGNA; PEREZ 2015; COSTAMAGNA; LARREA, 2017). 
Rodríguez, Montero, Pérez y García (2018) señalan que la gestión del conocimiento revaloriza también el saber extra académico en los procesos de desarrollo. Su fundamento es analizado en el modelo Triple Hélice Social como triada para el desarrollo y constituye parte del Modelo Municipio Inteligente, porque los conocimientos no son un recurso de un determinado sector, ellos existen en todos los sectores de la sociedad y esa cualidad, si se ejercita en un territorio, puede contribuir al diálogo y a la cohesión social. Un instrumento tan versátil y estratégico como la gestión del conocimiento no se puede mantener en los predios de la vida empresarial, con fines específicamente económicos, porque la dinámica que encierra puede contribuir al florecimiento de todos los demás procesos que se gestan en la sociedad para el desarrollo desde una perspectiva (inter) transdisciplinaria.

La clave de la construcción de conocimiento es la existencia de un ciclo dinámico de conversión del conocimiento, de tácito a explícito y de explícito a tácito, a través de procesos de interacción social en grupos de trabajo o en el conjunto de la organización. Esta es la dimensión ontológica del conocimiento, y mediante la conceptualización del conocimiento y su posterior aplicación, se evidencia la dimensión epistemológica del mismo; lograr la comunicación del conocimiento tácito no es una tarea común, ni fácil, porque para que pueda ser socializado debe ser sustraído del contexto personal y formalizarlo.

\section{MUNICIPIO INTELIGENTE Y DESARROLLO LOCAL RELACIÓN INDISPENSABLE PARA LA SOSTENIBILIDAD}

El Modelo Municipio Inteligente por un Desarrollo Local para su concepción exige una sistematización de los referentes relacionados con el desarrollo para su permanente vigencia y actualización. En este caso, se relacionan los conceptos e historia del desarrollo, las dimensiones del desarrollo, las teorías y enfoques sobre el desarrollo y los paradigmas de desarrollo. Además, se incluyen los referentes relacionados con el marco prospectivo del cambio de época y los paradigmas emergentes, el modelo Municipio Inteligente por un Desarrollo Local Sostenible y los procesos para su consecución en la gestión y educación para el desarrollo (RAMOS et al., 2016).

Un municipio inteligente se considera aquel en que un grupo de actores, que no tienen por qué ser extraordinarios, por el hecho de trabajar de una manera determinada pueden producir resultados extraordinarios. Ese plus es gracias a la interacción social. En más de 15 años se han abierto paso experiencias innovadoras que ayudan a plantear de una manera sistemática lo que se podría llamar una gestión más inteligente de los municipios. Para ello se debe afrontar con valentía los procesos de cambio y transformación local, que cobran más importancia, si cabe, en tiempos de crisis. En efecto, las crisis aunque sea un argumento muy manido ofrecen oportunidades, pero sobre todo plantean la necesidad de hacer las cosas de otra manera, de ajustar las estructuras y talentos humanos, de reformar las organizaciones y, en fin, de innovar. En el contexto actual, por su elevada complejidad, es imprescindible la construcción de iniciativas de solución a los problemas, haciendo uso del ingenio y la inventiva (BRITO; ARTIGAS; MARTINEZ, 2017).

El municipio inteligente se concibe como un espacio delimitado, territorial y geográficamente, en donde convergen las iniciativas locales a través del esfuerzo concertado de los diferentes actores que hacen vida en las comunidades, con el fin de llevar adelante la gestión pública de una forma más participativa y democrática. Esta acción se focaliza en el ámbito político territorial del municipio, y resulta de la agrupación de actores sociales, los cuales conservan sus particularidades 
endógenas y características autóctonas, lo que constituye una de las principales características (SOUZA; AWAD, 2012; BOUSKELA et al., 2016).

Mujica, Marín y Lovera (2009) señalan ingredientes, a lo que se considera por los autores de este artículo como municipio inteligente. En este, es el colectivo quien lleva adelante las acciones para el logro del desarrollo local, buscando el control social y orientando las políticas públicas en función del beneficio de las comunidades, con el objetivo de compartir los saberes y propiciar el encuentro entre el conocimiento, las necesidades y el talento, a fin de generar estrategias para potenciar su propio proceso de desarrollo.

Tres son los procesos más generales para la consecución de municipios inteligentes. En primer orden, es necesario establecer la base teórica y metodológica para el desarrollo a construir; un segundo proceso se relaciona con la gestión para el desarrollo; y el tercero, con la educación para el desarrollo. Estos propician la relación multidimensional del desarrollo, a partir de la acción social de los actores locales y sus instituciones, en la organización social para la toma de decisiones, contribuyendo con la participación de todos los miembros de un territorio determinado, los cuales hacen vida activa dentro de la misma, con compromiso de gestión social (RAMOS et al., 2016).

Cabe agregar que la organización que asimila nuevos conocimientos de manera tal que los actores aprenden a través del trabajo conjunto en una práctica cotidiana, posibilita el desarrollo sostenible del colectivo (DUBOIS, 2014). En municipios inteligentes esto se traduce de forma tal que este contexto puede concebirse como una red de curvas de aprendizaje. Esto sería un municipio que contempla, en su dinámica, ciclos consecuentes de acción, información, interpretación, experiencia, reflexión, sistematización, diálogo de conocimientos, aprendizaje, innovación y comunicación.

En los resultados parciales alcanzados en los municipios en que se investiga y se actúa, ha sido determinante la existencia de un liderazgo y de una organización anuente al cambio. En la medida en que se trata de acciones grupales, es indispensable contar con un liderazgo cooperativo, participativo, que reconozca el valor agregado del trabajo en equipo, con sensibilidad y conciencia, flexible, abierto a lo nuevo, y representativo de la organización. Un liderazgo de esta naturaleza va de la mano de un gobierno que posee diversas cualidades que favorecen y sostienen los impulsos innovadores (DE SOUZA, 2008; VILLATORO, 2016).

En este propósito, un líder debe manifestar voluntad de cambio, así como capacidad estratégica, para conducir las innovaciones hasta sus últimas consecuencias. La innovación se desarrolla o contextualiza más fácilmente allí donde existe disposición interna para el cambio. Esta es una lección importante para los actores sociales gestores de diversa índole, pues la semilla de la innovación requiere de un terreno fértil para germinar. Los municipios inteligentes son aquellos que, ante todo, sus actores son receptivos a las nuevas ideas. La táctica es avanzar en espiral, desde los grupos más interesados hacia los menos advertidos, con una voluntad sostenida para obtener mejoras continuas. (MUJICA; MARÍN; LOVERA, 2009; OJEDA; RAMOS, 2013).

La innovación surge del cruce entre diversos procesos, donde la teoría se encuentra con la práctica, donde los innovadores intercambian su experiencia, las organizaciones estatales y no estales cooperan, el conocimiento científico se complementa con el tradicional que proviene de la propia experiencia, y la necesidad práctica se encuentra con la generación de conocimiento aplicable. Esto requiere, por tanto, síntesis de ideas y condensación de alternativas, y conjunción de conocimientos diferentes que puedan complementarse. Por esto, ha cobrado tanta importancia 
la integralidad de los proyectos en la selección, pues esa es la respuesta a la complejidad propia de la innovación en el campo social. La integración de conocimientos, disciplinas, grupos, organizaciones, instituciones, es más viable en la escala local, donde tiene lugar la mayor parte de las innovaciones (SOUZA; AWAD, 2012; BOUSKELA et al., 2016; BRITO; ARTIGAS; MARTíNEZ, 2017).

El hecho de construir un municipio inteligente exige un modelo de participación diferente, el modelo de participación de la población en la toma de decisiones, que en la práctica es un elemento crucial y transversal en la consideración de uno u otro enfoque de actuación comunitaria cuando se está en presencia de un municipio inteligente. La participación se puede considerar y gestionar desde diferentes formas e intensidades. De manera sustantiva o como proceso, promoviendo el acceso real de todos los actores sociales a la toma de decisiones en la elaboración, ejecución y evaluación de políticas y programas sociales o, por el contrario, subordinada a las actuaciones profesionales y directrices políticas, siendo un simple medio cuyo objeto es legitimar políticas, programas y actuaciones profesionales. De esta forma, la participación puede variar en un continuo desde el puro simbolismo a la integración completa en todas las fases de los procesos de decisión (OJEDA, 2012).

En municipios inteligentes los procesos descentralizadores suponen un mayor protagonismo de los actores sociales en la definición de su gestión para el desarrollo, de la planificación estratégica desde la complejidad y con visión holística, de las líneas estratégicas del desarrollo municipal, así como en la gestión y evaluación de proyectos con base municipal. Para que la estrategia de desarrollo en municipios inteligentes emerja, es necesaria la colaboración o creación de espacios en los que se compartan informaciones y experiencias, y se expliciten los consensos y disensos existentes. Estos espacios de diálogo tienen que tener cierta continuidad para que se tenga oportunidad de explorar la diversidad de perspectivas, experiencias, proyectos y propuestas que existen en el territorio. Estos diálogos son los que hacen que los actores pasen de tener su propia misión y objetivos a que los mismos converjan con una misión y objetivos de sistema compartidos (KARLSEN; LARREA, 2014, 2015; SOLER, 2017).

La consecución de Municipio Inteligente por un Desarrollo Local supone para el investigador social un reto importante, pues se trata no de analizar la innovación social desde fuera, sino de construirla en interacción con los demás actores del territorio. Ello conlleva situaciones de conflicto y elevada complejidad. Para superar estas situaciones y construir las interacciones señaladas, la investigación acción propone el concepto de conocimiento colectivo en la acción. Se trata de una capacidad colectiva que solo puede construirse en procesos dialógicos vinculados a la acción. Nunca consiste en capacidades potenciales o teóricas, ni en prescripciones normativas. Por lo tanto, entrar en estos procesos requiere que el investigador construya espacios de diálogo con los actores y asuma su rol de actor municipal que, como los demás, tiene un posicionamiento ideológico sobre los retos abordados (KARLSEN; LARREA, 2015).

Sin dudas, la consecución de municipios inteligentes y el desarrollo forman una unidad imprescindible para el desarrollo local; pues para alcanzar la inteligencia municipal y el desarrollo local se precisa de atributos del nuevo modo de generación de conocimiento como son: conocimiento generado en el contexto de su aplicación e implicaciones, relación transdisciplinaria, diversidad de actores y organizaciones, reflexividad y compromiso sociales, además de control social. Frecuentemente se ha intentado captar y comprender fenómenos sociales bajo las mismas premisas de la exactitud científica con la que se intentaba explicar los fenómenos de la naturaleza; 
esas ideas más mecanicistas indujeron a una separación de la economía, la política y lo social. También se ha intentado separar la dimensión técnica de la política como si esto siempre fuese posible (COSTAMAGNA; LARREA, 2017).

\section{TEORÍA Y ENFOQUES DEL DESARROLLO EN MUNICIPIOS INTELIGENTES}

El desarrollo local sostenible se centra en la búsqueda del mejoramiento de la calidad de vida humana en el ámbito local (CARVAJAL, 2011), por lo que, con la consecución de municipios inteligentes, la construcción de desarrollo local es más viable a partir del protagonismo real de las personas familias, niños, productores, organizaciones e instituciones locales. Mientras se analiza desde la teoría este planteamiento, se afirma el mismo como una premisa para la sostenibilidad, sin embargo, las acciones, la visión que se posee para resolver la vulnerabilidad desde los paradigmas de desarrollo en conflicto paradigma neo-racionalista, paradigma neo-evolucionista, paradigma constructivista, crean incertidumbre y caos, pues la sostenibilidad se construye en el contexto, entonces el paradigma que se sigue no ha de ser otro que el constructivista. (DE SOUZA, 2010; BERTONI et al., 2011, DE SOUZA, 2014).

El desarrollo local se convierte en un nuevo paradigma de las teorías del desarrollo, alimentado con emergentes propuestas que van más allá del consolidado carácter endógeno que lo caracteriza casi desde sus inicios, para renovarse con otras basadas en la equidad, la sustentabilidad y la planificación participativa. Ello dará lugar a la concepción, teórica y metodológica que incentiven esos aspectos y sean base para la consecución de municipios inteligentes (OJEDA, 2012; RAMOS et al., 2016).

Un Municipio Inteligente por un Desarrollo Local Sostenible exige de una teoría o enfoque del desarrollo diferente a las teorías que han sustentado el desarrollo hasta el presente. Por ello, el cambio más significativo en el concepto de desarrollo se debe a la formulación de la teoría o enfoque del desarrollo humano que surge en el contexto antes expuesto del proceso de crítica a la economía del desarrollo dominante, que se caracteriza por proponer el crecimiento económico como objetivo. Por el contrario, el desarrollo humano afirma que este no debe ser el objeto central del desarrollo sino únicamente uno de sus referentes (PROGRAMA DE NACIONES UNIDAS PARA EL DESARROLLO [PNUD], 2011; DUBOIS, 2014).

Su propuesta supone un cambio radical de los planteamientos anteriores en dos sentidos: Uno, porque coloca el centro de la concepción del desarrollo en el proceso de expansión de las capacidades de las personas de manera que puedan elegir su modo de vida. Dos, porque cuestiona que el desarrollo dependa fundamentalmente de la expansión del capital físico y se resalta la importancia del talento humano. En definitiva, se sustituye una visión del desarrollo centrado en la producción de bienes, por otra centrada en la ampliación de las capacidades de las personas (BERTONI et al., 2011; PNUD, 2011; DUBOIS, 2014).

En el modelo de Municipio Inteligente por un Desarrollo Local, la visión del carácter multidimensional del desarrollo obliga a forjar estrategias (inter-trans) disciplinarias hacia el interior de la Universidad, con las distintas áreas del conocimiento. Ello es posible, cuando se extienden los muros fuera de la universidad y trasciende al gobierno y a la comunidad para descubrir y entender los problemas, identificar los posibles caminos para superarlos, y proponer acciones tendientes a su resolución, lo que se observa claramente en los análisis de (LAGUNA; MARCELÍN, 2016).

INTERAÇÕES, Campo Grande, MS, v. 22, n. 3, p. 977-1000, jul./set. 2021. 
En un municipio inteligente se realiza un análisis desde un pensamiento y actuación diferente en los ámbitos académicos en los que recaen las tareas de revisión y reflexión de las propuestas de una disciplina como el desarrollo, que ante todo tiene un componente aplicado de primer orden, que no ha logrado capacidades de generar un marco sólido y consensuado sobre lo que es el desarrollo local, las bases en las que tiene o puede sustentarse, y las estrategias disponibles para conseguir los objetivos perseguidos. Además, no tiene por qué excluir la convivencia de versiones multi paradigmáticas, e incluso confrontadas, sobre las diferentes formas de interpretar esa realidad. Hoy, son tan apremiantes las demandas de los que toman decisiones y el déficit de capacidades en los actores que conforman la triple hélice social en los municipios, que se es conducido de forma inexorable al inmediatismo pragmático. No hay tiempo para desarrollar una visión compleja de la vida y el desarrollo del "buen vivir" en ella; predomina la visión de una "sociedad máquina", la mirada materialista y mecánica de la realidad, lineal y determinista, dualista y reduccionista (DE SOUZA, 2010).

Karlsen y Larrea (2014) definen el concepto de complejidad municipal como un contexto en el que existe una serie de actores autónomos pero interdependientes en un territorio. Dichos actores pueden tener perspectivas distintas de cuáles son los principales problemas que tiene el municipio y también sobre cuáles son las posibles soluciones. El último elemento de la complejidad municipal es que ninguno de los actores cuenta con poder suficiente para solucionar los problemas que considera críticos mediante el ordeno y mando. Esto significa que, cuando hay una situación de complejidad, no funciona el ordeno y mando y es necesario desarrollar otro tipo de mecanismos. Es precisamente a este proceso de construcción de nuevos mecanismos a lo que contribuye la investigación acción para el desarrollo.

\subsection{Formación de capacidades para el desarrollo sostenible}

En el apartado anterior, se señaló por parte de los autores de este documento, que en la consecución de Municipios Inteligentes por un Desarrollo Local Sostenible era imprescindible, urgente y necesario, asumir la teoría del desarrollo humano como sustento teórico metodológico de dicho modelo. La asunción de dicha teoría no está dada a que rechace la visión anterior centrada en la producción de bienes, servicios o resultados, sino que, al referirse al desarrollo, no se trata del desarrollo de bienes o resultados, sino de resaltar la importancia del talento humano. Significa entonces, que se sustituye por una visión multidimensional, inter y transdisciplinaria centrada en la ampliación de las capacidades de las personas para lograr una gestión eficiente de los bienes, servicios y resultados, de manera que satisfagan las necesidades de las personas para su bienestar y prosperidad.

Una de las definiciones relacionadas con el desarrollo que se sistematiza es la planteada por (ALBURQUERQUE; COSTAMAGNA; FERRARO, 2008) Ios cuales aluden al proceso de construcción de capacidades cuya finalidad es mejorar de manera colectiva y continuada el bienestar de una comunidad. La construcción de capacidades como estrategia requiere de una comunidad que pueda organizarse en torno a dicha estrategia. Esto exige organización, interacción y distintas acciones con el fin de lograr una gestión que abarque a la sociedad en su conjunto.

Esta definición refleja una clara visión de proceso, dejando muy abierta la referencia al objetivo de la mejora del municipio, o el qué de la estrategia, y poniendo el tema de las capacidades en el centro de la escena. Al trabajar con esta definición centrada en el cómo del desarrollo municipal, se ha planteado con frecuencia que le falta un qué más claro: ¿Qué se 
quiere construir exactamente? ¿Puede la construcción de capacidades en sí misma ser el objetivo de una estrategia de desarrollo en municipios inteligentes? El posicionamiento es que es difícil anticipar los qué del desarrollo municipal antes de investigar a los actores de un municipio.

De esta manera, se replanteó la construcción del conocimiento, entendiéndola como algo colectivo en donde el punto de partida es el reconocimiento de los saberes de los actores y su puesta en diálogo con los saberes del formador/persona facilitadora para intentar co-construir. Esto permite, entre otras variables, incorporar lo contextual y la idea de proceso y con eso generar un puente entre la crítica a la formación en el aula y la necesidad de ser coherente entre teoría, enfoque y práctica en municipios inteligentes (COSTAMAGNA; SPINELLI; PÉREZ, 2013).

El modelo Municipio Inteligente asume estas perspectivas, y en línea con los fundamentos teóricos y metodológicos que lo sustentan de manera crítica, porque a veces se repiten recetas sin tener en cuenta quiénes son los interlocutores y dónde transcurrían sus experiencias. De esta forma, se valora el conocimiento situado, lo que permite explicitar que la formación transforma con mayor énfasis cuando se vincula con las realidades locales del día a día y conecta la teoría con la práctica (COSTAMAGNA; LARREA, 2017).

El enfoque pedagógico, según (COSTAMAGNA; LARREA, 2017) permite el entendimiento y la actuación en la construcción de capacidades para el cambio en el municipio de forma coherente con una construcción social y política que active la participación de los actores de la triple hélice para el desarrollo. Esto supone un modo de comprender el conocimiento, la vinculación teoríapráctica, el reconocimiento de los otros saberes locales, prácticas y experiencias la vinculación basada en el diálogo y la resolución de conflictos promoviendo instancias democráticas.

La formación de capacidades en la consecución de Municipios Inteligentes para el Desarrollo Local es un proceso mediante el cual los individuos, grupos, organizaciones, instituciones, comunidades y sociedades incrementan su información, conocimientos, habilidades, actitudes, valores, para realizar funciones esenciales, resolver problemas, definir y lograr objetivos, y entender y responder a sus necesidades de desarrollo en un contexto y de manera sostenible, lo cual posibilita una gestión para el desarrollo eficiente (RODRÍGUEZ; FERNÁNDEZ; PÉREZ, 2015). Ello implica cambio de paradigmas, cambio personal y organizacional, mejora de la calidad de las prácticas, y cambios de comportamientos.

En el modelo Municipio Inteligente por un desarrollo local, la formación de capacidades funcionales es determinante para la construcción social de conocimiento y para la innovación social del conocimiento desde el contexto de actuación. El modelo teórico Municipio Inteligente se genera desde la academia pero en cada municipio se construye en la relación Gobierno Universidad - Comunidad desde el gobierno, con el gobierno y en el gobierno, y solo se hace realidad con la formación de capacidades funcionales para que los actores involucrados participen, para diagnosticar una situación y definir una visión de encargo social, con capacidad para formular políticas y estrategias, capacidad para gestionar planes, programas y proyectos para el desarrollo, capacidad para evaluar, y para integrar desde la triple hélice social para el desarrollo (PINEDA; MORALES; ORTIZ, 2012; LUENGO; OBESO, 2013; BRITO; ARTIGAS; MARTÍNEZ, 2017).

En la formación de capacidades para el desarrollo asumida en el Modelo Municipio Inteligente se plantea como argumento central que intentos recurrentes de solucionar el mismo problema conlleva implícitamente un tratamiento de dicho problema como complicado. Es decir, se entiende que lo que se requiere es capacidad de analizar y los líderes se apoyan frecuentemente en expertos. La reflexión que se plantea es que estos procesos no son complicados, sino complejos. 
En las relaciones complejas no hay una respuesta adecuada que se pueda desentrañar, los planteamientos se hacen en el contexto de un proceso donde las cosas suceden sin que se tenga el control de todo y aparecen temas que no estaban en la agenda. Sin embargo, aun tomando la definición de complejidad que proponen (GARCÍA, 2011; BECERRA, 2014), hay algo que exponer de forma distinta. Ellos señalan que en estos casos los líderes, más que intentar imponer un curso de la acción, deben permitir pacientemente que el camino hacia delante se revele. Se considera que, sin necesidad de esperar a que las cosas ocurran, el camino se puede construir, pero no en forma de implementación de una solución derivada del análisis de expertos, sino como un proceso de construcción social con diversos intereses, actores y tiempos (COSTAMAGNA; LARREA, 2017).

\subsection{Estado actual de las capacidades en el desempeño de los actores sociales para la consecución de municipio inteligente por un desarrollo local}

Si anteriormente se señalaba que la consecución de municipios inteligentes desde la teoría del desarrollo humano supone un cambio radical de los planteamientos anteriores, ya no se trata de la consecución de un municipio desde una visión unidimensional, disciplinar del desarrollo, es decir, exclusivamente economicista, donde el centro es la producción de bienes, servicios y resultados. Ahora se trata de construir un municipio al que se llamará inteligente porque coloca el centro del desarrollo en el proceso de formación de las capacidades de las personas de manera que puedan elegir su modo de vida y contribuir a la eficiencia en la producción de bienes y servicios con conocimientos, habilidades, actitudes, valores y prácticas en el desarrollo municipal.

Las capacidades y competencias para la gestión del desarrollo, permiten contar con un talento humano más capaz para gestionar la organización inteligente. La formación de capacidades para la gestión del desarrollo permite a las organizaciones contar con un talento humano más capaz en un entorno globalizado. Para ello se identifican tres elementos que generan cambios no solo en las personas sino en las organizaciones y el entorno: la teoría de los recursos y capacidades, la innovación, la gestión de innovación y, por ende, estos elementos contribuyen al desarrollo de competencias interculturales (NINO; VÉLEZ; LARA, 2010; DUBOIS, 2014; BAQUERO; RENDÓN, 2014).

Teniendo en cuenta un modelo causa-efecto, las capacidades y competencias para la gestión del desarrollo serán el resultado de considerar simultáneamente la gestión estratégica, tecnológica, de innovación, de conocimientos y de proyectos, reconociendo el valor de la innovación y no limitándose a considerar aspectos netamente tecnológicos o comerciales. Asimismo, la teoría de los recursos y capacidades enfatiza que en el análisis de la organización será necesario no sólo identificar el tipo de recursos y capacidades sino cómo lograr desarrollarlas y potenciarlas para lograr tener una propuesta de gran valor y eficiencia en sus resultados, productos y servicios. El resultado de esta situación será obviamente una ventaja competitiva sostenible y generación de valor (PNUD, 2010; DUBOIS, 2014).

En la teoría del recurso y las capacidades se plantea que el entorno es cada vez más complejo, dinámico e interrelacionado. En este contexto la organización se encuentra en la obligación de cambiar para garantizar su propia supervivencia. Si la organización debe cambiar, esta debe ser entendida como un sistema cambiante, en el cual interactúan variables de entorno y variables internas (DUBOIS, 2014; BRITO; ARTIGAS; MARTINEZ, 2017; COSTAMAGNA; LARREA, 2017).

Las organizaciones que emplean personas nunca son completamente estáticas, dado que son sistemas sociales abiertos interactuando con sus entornos. Las organizaciones son y 
se comportan como seres vivos, y para sobrevivir deben convivir con su medio, adaptándose y co-evolucionando con el entorno (ARBONÍES, 2007).

Seguidamente, este autor expresa que las nuevas formas organizativas se basarán en una evaluación con el entorno: co-evolución, un cambio sustancial en la forma de entender la organización como algo físico, para pensar en una organización como fluido, preparada para acometer la complejidad y los eventos inesperados. Una implicación con el entorno en términos sociales, territoriales y emocionales, con uso intensivo de las tecnologías de la información y las comunicaciones, para establecer redes en una ecología innovadora, un liderato diferente que más que delegar o dar poder a las personas, organizará relaciones y visiones compartidas (PNUD, 2011; KARLSEN; LARREA, 2015; COSTAMAGNA; LARREA, 2017; BRITO; ARTIGAS; MARTÍNEZ, 2017).

El estudio sobre el estado actual de las capacidades en los actores sociales para la consecución de Municipio Inteligente por un Desarrollo Local durante el año 2019 se centró en una muestra de 107 actores de la Universidad - Gobierno - Comunidad en su imprescindible integración para la gestión del desarrollo en el municipio. Un primer momento de la investigación estuvo dedicada al análisis, interpretación y reflexiones de los comportamientos de los actores sociales de la triple hélice para el desarrollo en la consecución de municipios inteligentes por un desarrollo local sostenible desde la gestión del conocimiento, como responsabilidad social de la universidad.

A continuación, se presentan determinados ítems para su análisis e interpretación. Primero, fueron identifican las siguientes capacidades funcionales que serán objeto de evaluación, análisis, interpretación y reflexiones por los actores sociales para la construcción de Municipios Inteligentes por un Desarrollo Local.

Capacidades Claves: 1. Establecer objetivos. 2. Elaborar estrategias. 3. Elaborar planes, programas y proyectos de acción. 4. Diseñar e implementar políticas apropiadas. 5. Establecer marcos legales y de regulación. 6. Crear y gestionar alianzas. 7. Fomentar un entorno propicio para la sociedad civil, especialmente para el sector privado. 8. Movilizar y gestionar recursos. 9. Implementar planes de acción. 10. Monitorear los progresos.

Capacidades Centrales: 1. Guiarse por valores clave y un sentido del fin. 2. Definir y analizar su entorno y su lugar en el esquema más amplio de las cosas. 3. Capacidad de análisis y visión de futuro. 4. Definir las cuestiones y alcanzar acuerdos que funcionen sobre los objetivos o mandatos. 5. Gestionar y resolver conflictos. 6. Capacidad de relacionarse y conseguir apoyos. 7. Formular estrategias. 8. Planificar y actuar en base a los planes. 9. Conseguir y movilizar recursos. 10. Aprender nuevas habilidades y enfoques de manera continua. 11. Capacidad de equilibrar coherencia con diversidad. 12. Establecer relaciones de apoyo con otras partes. 13. Evaluar los resultados y hacer ajustes. 14. Enfrentar proactivamente los nuevos desafíos, ajustando agendas, enfoques y estrategias. 15. Capacidad de adaptarse y renovarse.

Capacidades en Municipios Inteligentes: 1. Fundamentos teóricos y metodológicos para la consecución de Municipios Inteligentes. 2. Para aprender, desaprender y reaprender desde el contexto de actuación en que se desempeñan. 3. Para trabajar en equipos en la construcción social de conocimientos. 4. Para trabajar en una relación horizontal, donde se es también "sujeto" de la investigación con una visión holística, integrada y transdisciplinaria de las necesidades y problemas del contexto. 5. Para construir socialmente su realidad desde su contexto. 6. Para construir su realidad con participación e interacción social. 7. Para llegar a negociar y consensuar con el deber ser. 8. Para construir su realidad contextual desde enfoques complejos, holísticos y 
transdisciplinarios. 9. Para la producción de teorías e instrumentos para comprender y transformar el territorio. 10. Para actuar desde la triple hélice social para el desarrolló en su contexto. 11. Aprendizaje, autorreflexión y autocrítica, combinar diferentes tipos de conocimiento, incorporar el conocimiento local en la gestión y la toma de decisiones.

En la investigación se diseñaron cuatro instrumentos para la valoración de las capacidades que poseen los actores sociales en la consecución de Municipios Inteligentes por un Desarrollo Local. En un primer momento cada instrumento se aplicó a la diversidad de actores participantes en la investigación, en este caso 107 actores provenientes de la universidad, del gobierno y la comunidad. El procedimiento para la aplicación de los instrumentos y la caracterización de las capacidades funcionales en los actores se realizó de la siguiente manera.

En un segundo momento los instrumentos se entregaron a los actores en dos talleres realizados para que los actores hicieran un análisis, reflexión desde la percepción e interpretación que tienen sobre las capacidades funcionales que poseen para la Gestión del Desarrollo desde su desempeño profesional. Una vez realizado los talleres, se valoraron los cuatro instrumentos para determinar las percepciones que poseen los actores locales sobre sus capacidades funcionales para la gestión del desarrollo.

En un tercer momento de la investigación se realizaron talleres de investigación con el empleo de métodos tales como, entrevista grupal, observación participante, trabajo en equipos realizados en un taller de investigación en la solución de situaciones relacionadas con la gestión para el desarrollo, y las propuestas de solución. Estos métodos utilizados parten de los instrumentos aplicados al inicio, creando diversas situaciones que permitieron cruzar la información de los instrumentos aplicados al inicio, con la información brindada por los métodos aplicados en los talleres de investigación.

\subsection{Análisis y reflexiones}

A continuación, se analizan en interacción las capacidades claves + capacidades centrales + capacidades en Municipios Inteligentes desde una visión holística, inter y transdiplinariamente. Para ello, se presenta la Tabla 1. 
Tabla 1 - Valoración de los instrumentos aplicados en la investigación

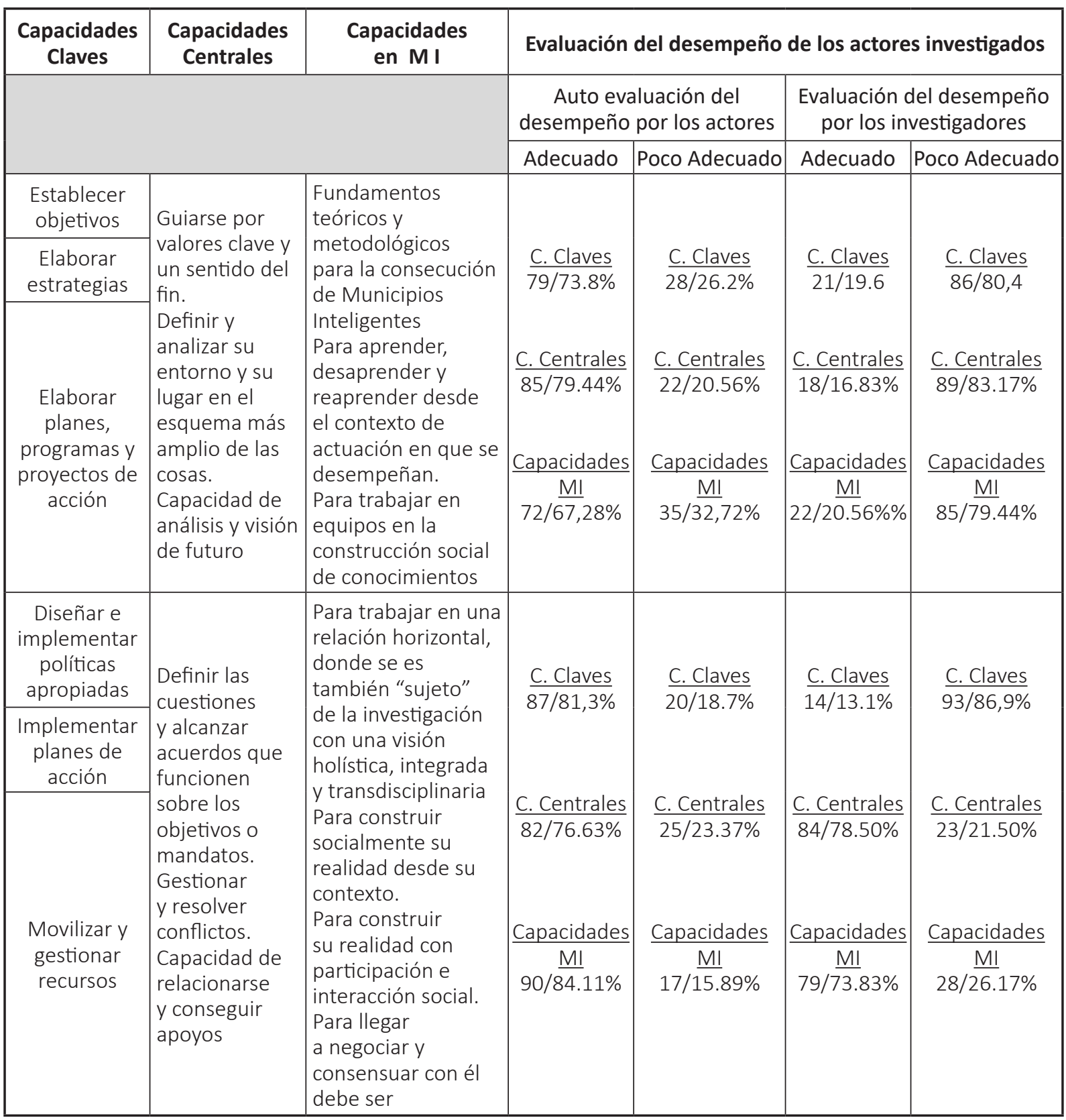

Fuente: Elaborado por los autores con datos de los instrumentos aplicados.

Para el análisis y reflexiones se siguieron los siguientes pasos:

1 - Saber qué: Datos, estadísticas, para conocer y controlar la realidad. En este caso, la caracterización de las capacidades y funcionamientos de los actores sociales en el momento de la investigación.

El saber qué, presentado en la Tabla 1 permite observar datos y estadísticas en lo relacionado con la auto evaluación del desempeño de los actores sociales participantes, y la evaluación del desempeño realizada por los investigadores a los propios actores sociales. Es preciso señalar que tanto en la autoevaluación como en la evaluación se tomaron como base los cuatros instrumentos señalados anteriormente, con la diferencia de los métodos y procedimientos utilizados en el primer y segundo caso. Sin embargo, los datos y estadísticas que refleja esta tabla, permiten 
apreciar valores contradictorios entre la autoevaluación realizada por los actores y la realizada por los investigadores en los mismos actores y sobre la base de los mismos instrumentos.

Los actores sociales se autoevalúan, en relación a las capacidades claves estudiadas en un primer grupo como son, establecer objetivos, elaborar estrategias, elaborar planes, programas y proyectos de acción, diseñar e implementar políticas apropiadas, en un $73.8 \%$ de poseer desempeño adecuado en estas capacidades, mientras el $26,2 \%$, se autoevalúan de poco adecuado en el desempeño en estas capacidades. En la propia tabla, en la evaluación realizada por los investigadores sobre la base de los propios instrumentos, pero con la utilización de métodos como, la entrevista grupal, la observación científica, el taller de investigación y el diálogo de saberes, los datos reflejan lo contrario, se posee un desempeño adecuado solo en el 19,6\% de los actores evaluados.

En el primer grupo analizado en relación a las capacidades centrales y en las capacidades necesarias en la consecución de municipios inteligentes, se presentan datos y estadísticas similares. En el caso de las capacidades centrales, la autoevaluación realizada por los actores refleja valores adecuados de desempeño en el $79.44 \%$ y de poco adecuados en el $20.56 \%$ de los actores sociales. En relación a la evaluación realizada por los investigadores respecto a las capacidades centrales, esta arroja valores de desempeño adecuado en el $16.83 \%$ y de poco adecuados en el $83.17 \%$ de los actores sociales estudiados.

2 - Saber por qué: Información; análisis para la interpretación y comprensión de datos, hechos y estadísticas sobre las capacidades y funcionamientos que poseen los actores sociales para comprender la realidad.

La situación problemática de partida radica en la necesidad de fortalecer el proceso de gestión del conocimiento entre la universidad, los gobiernos municipales y la comunidad, como parte del proceso de formación continua de capacidades y competencias de los actores locales en la consecución de Municipios Inteligentes por un Desarrollo Local Sostenible. Ello implica la solución de las insuficiencias que se manifiestan en la realidad municipal tradicional durante la realización de dicho proceso, por la contradicción existente entre las capacidades que poseen los actores sociales y las que deben poseer para construir un Municipio Inteligente por un Desarrollo Local Sostenible.

En el análisis y observaciones realizadas se percibe e interpreta una contradicción entre el "debe ser" en la realidad y lo que "es". Esta contradicción está dada por una visión del desarrollo centrado en la producción de bienes con énfasis en la dimensión económica que se pone en práctica en municipios tradicionales, y el enfoque de desarrollo humano centrado en la ampliación de las capacidades de las personas con un carácter multidimensional: social, cultural, económico, ambiental, político; con relaciones inter y transdiplinarias indispensables para la consecución de municipios inteligentes.

Más allá de que estas ópticas pueden aportar instrumentos, herramientas, teorías o incluso información relevante para abordar estos temas, esas ópticas son de por sí insuficientes tanto para entender el problema en su complejidad como para actuar en dirección a su resolución. Sin dudas el desarrollo es uno de esos problemas que no puede ser abordado exclusivamente con miradas disciplinarias. Como se ha dicho, todas las miradas disciplinarias, ya sea desde la física, la biología, la economía, la sociología o la historia tienen aportes muy importantes que hacer para la comprensión del desarrollo. Sin embargo, todas ellas pueden resultar construcciones antojadizas al momento de estudiar esta problemática, y proponerse acciones de transformación social. 
La consecución de municipios inteligentes no es posible con un análisis lineal, mecánico, unidimensional y disciplinar, donde prime el desarrollo de las cosas u objetos, sino en las capacidades y competencias que se poseen por los actores para la construcción de Municipios Inteligentes por un Desarrollo Local, lo que confirma la frase pensar y actuar de manera diferente. De esta manera se confirma el por qué la contradicción entre los resultados de la autoevaluación realizada por los actores sociales y la realizada por los investigadores a dichos actores. Los actores asumen la transformación del contexto pensando y actuando con los mismos conocimientos, habilidades, actitudes, valores y prácticas de otra época, en que la multidimensionalidad, interdisciplinariedad, y el enfoque de la complejidad no eran necesarios para ese modelo de desarrollo.

En este sentido, partiendo de los resultados de las autoevaluaciones de los actores sociales y valoraciones anteriores y de la información y conocimiento que se posee en el CEGED, se pueden plantear un grupo de limitantes, barreras, de insuficiencias de capacidades, que atentan en el entendimiento y comprensión del desarrollo y de su construcción en el contexto municipal. Estas explican el por qué la forma de pensar y actuar de los actores sociales:

- Conceptos del desarrollo local que son incompletos, que se repiten por los actores sin una reflexión y análisis previo, con una percepción e interpretación que no es coherente con la teoría y acción del desarrollo que se pretende construir.

- Las teorías sobre el desarrollo se asumen por los actores que poseen o dicen poseer conocimientos y entendimiento sobre dicho proceso, sin embargo, el discurso teórico no es coherente con la práctica, es decir, una cosa es lo que debe ser por los actores y otra es lo que se hace en la consecución del desarrollo.

- La formación deficiente que se tiene por los actores de la triple hélice social para el desarrollo - Universidad - Gobierno - Comunidad sobre consecución del desarrollo local.

- La formación de profesionales en las diferentes carreras y áreas del conocimiento que forman capacidades técnicas que les permite conocer y controlar el objeto, y no capacidades funcionales necesarias para comprender y transformar el contexto-aspectos imprescindibles para la construcción del desarrollo-.

- En la formación desde el posgrado en el área del conocimiento del desarrollo - se desintegra su visión multidimensional en la ejecución de maestrías, especialidades, doctorados, e inclusive, el análisis hecho por especialistas se hace desde la disciplina de cada cual, pero sin una visión integrada de las diferentes disciplinas o de las dimensiones del desarrollo.

- Al asumir el desarrollo como un proceso de gestión social, de carácter complejo, multidimensional, inter - transdiciplinariamente, cada área del conocimiento, debe asumir no solo formar las capacidades técnicas propias para un ingeniero, licenciado, sino además las capacidades funcionales que debe poseer al graduarse, en la que debe tributar a la gestión del desarrollo sostenible con capacidades que le permitan pensar en un análisis multidimensional e interdisciplinariamente, en la gestión, planificación, proyección para el desarrollo.

3 - Saber cómo: Capacidades: conocimientos, habilidades, actitudes, valores y prácticas. Acciones intelectuales del actor que lo faculta para transformar la realidad: investigar, sistematizar, diseñar, ejecutar metodologías, planes, programas y proyectos para transformar y 
cambiar la realidad. Competencias: potencialidades funcionales de las facultades de los actores. Aptitudes que les permiten actuar en la diversidad de realidades para cambiar en otra realidad cualitativamente superior.

Por lo general las investigaciones quedan en el qué, lo cual permite conocer para controlar y no propiamente lo que es imprescindible para la gestión del desarrollo, comprender para transformar, por lo que debe transitar por el qué, por qué y cómo, lo que es posible desde lo cualitativo. En la investigación realizada se pone de manifiesto que en la actualidad los actores intentan construir el desarrollo desde un sustento teórico centrado en la producción de bienes, servicios y resultados, donde lo esencial es lograr los bienes, resultados en cantidad, descuidando la calidad y eficiencia de los resultados y bienes, que se logra si el sustento teórico descansa en ampliación de las capacidades de las personas.

Asimismo, para que los investigadores sociales puedan jugar este papel en la Investigación Acción en el Desarrollo (IAD) es necesario construir espacios de diálogo con los actores. Para ello se propone el Taller de Investigación, definido como espacio en el que la ciencia habla a los actores y los actores responden a la ciencia. Es el ámbito de hecho, muchos ámbitos en el que tiene lugar la contextualización y en el que el conocimiento se va haciendo socialmente sólido, al estar constantemente sometido a prueba. Ni Estado, ni mercado, ni exclusivamente privado, ni exclusivamente público, el taller es un espacio en el que se enmarcan y definen problemas sociales y científicos, y en el que se negocia lo que finalmente va a ser aceptado como una solución.

Es imprescindible en el cómo transformar la realidad, la capacidad colectiva-conocimientos, habilidades, actitudes, valores y prácticas en la acción, esto se genera en el contexto de aplicación, siendo imposible separar reflexión de la acción, la teoría de la práctica; se trata, pues, de una capacidad basada en el concepto de praxis. La apuesta de los investigadores por este tipo de aproximaciones no siempre es fácil, pues los tipos de marcos conceptuales derivados de la praxis son frecuentemente considerados menos sofisticados que los exclusivamente generados desde la teoría, y son más difícilmente aceptados como resultados académicos relevantes (COSTAMAGNA; PÉREZ, 2015; RODRÍGUEZ; MONTERO; PÉREZ; GARCÍA, 2018). Sin embargo, su capacidad de generar cambio en el territorio es, desde la perspectiva de la Investigación Acción para el desarrollo, superior.

Saber el cómo se construye un Municipio Inteligente por un Desarrollo Local Sostenible desde la Gestión del Conocimiento es codiciado por la diversidad de actores que desde sus funciones han de contribuir al desarrollo sostenible en sus contextos de actuación. Los actores han de pensar y actuar de manera diferente pues el desarrollo es un proceso de gestión social en la cual la realidad municipal es socialmente construida y transformada desde el conocimiento generado de forma interactiva en el contexto municipal.

En la forma de pensar y actuar de los actores de los municipios estudiados prevalece la forma tradicional de buscar fórmulas, modelos y recetas previamente construidas en otros contextos o municipios, sin consideración de los valores, las necesidades, las aspiraciones, etc., de los actores del contexto de su aplicación e implicaciones, obviando que el desarrollo sostenible no se somete a seguir rutas, procedimientos, al contrario lo gestiona y lo construye en interacción con los actores municipales.

Sigue latente en los actores del desarrollo y lectores encontrar en el documento el cómo se logra Municipios Inteligentes por un Desarrollo Local. Cabe agregar, que los autores del artículo en realidad facilitan el proceso de construcción no solo desde la universidad sino con la integración 
de la Triple Hélice Social para el Desarrollo - Universidad-Gobierno-Comunidad - como proceso de integración, gestión, construcción e interacción social. Es oportuno agregar, que las pautas y protocolo a seguir en la construcción de un Municipio o Contexto Inteligente no es generalizable a otros contextos, pues depende en buena medida de las capacidades y competencias de los actores de la triple hélice social para su construcción y no propiamente del resultado del Municipio Inteligente por un Desarrollo Local Sostenible como modelo para el desarrollo.

Significa entonces, que los actores, lectores no encontrarán la fórmula o receta en la construcción de Municipios Inteligentes por un Desarrollo Local Sostenible, sino los análisis, reflexiones y resultados que han permitido ir construyendo paso a paso determinados contextos inteligentes a partir de las capacidades y competencias que poseen los actores sociales de la triple hélice para el desarrollo en el contexto de actuación. En este propósito, se señala el cómo desde la función social de la universidad en la gestión del conocimiento desde los procesos universitarios de ciencia - innovación - extensión en la formación de capacidades y competencias de los actores sociales en la construcción de Municipios Inteligentes por un Desarrollo Local Sostenible.

La investigación en los municipios en la construcción de su desarrollo sostenible ha seguido un protocolo que posibilita el cómo en el contexto de actuación municipal con la integración de la triple hélice para el desarrollo, de la triada aprender, desaprender y reaprender, y de un modelo de desarrollo sostenible para municipios inteligentes tracen la ruta con la participación de todos actores los en la construcción del desarrollo siguiendo las pautas suficientes y necesarias para su logro: Las pautas en está ocasión desembocaron en resultados del Municipio Inteligente en la construcción de su Desarrollo Sostenible. Todo modelo de desarrollo orientado éticamente debe caracterizarse por ser: incluyente, humano, sostenible, participativo, ético, equitativo, social, autogestionable e integral, principios esenciales en la construcción de un municipio inteligente por un desarrollo local sostenible. A continuación, una síntesis de los fundamentos teóricos metodológicos o pautas como resultados alcanzados en la consecución de Municipios Inteligentes por un Desarrollo Local Sostenible.

\subsubsection{Paradigma de investigación: socio-crítico}

La concepción sociocrítica, recoge como una de sus características fundamentales, que la acción o estudio sobre la práctica local, se lleve a cabo a través de procesos de autorreflexión, que generen cambios y transformaciones de los actores protagonistas, a nivel municipal. En el marco del paradigma de investigación asumido para la consecución de Municipios Inteligentes por un Desarrollo Local, se apuesta por la necesidad de incluir a las personas como sujetos activos capaces de pensar por sí mismos y de ser generadores de cambio. La investigación acción participativa se convierte en una alternativa metodológica, innovadora y capaz de generar profundos cambios a nivel social.

\subsubsection{Enfoque de investigación: Cualitativo-Mixto}

Dadas las condiciones que anteceden, en la consecución de Municipios Inteligentes por un Desarrollo Local Sostenible el enfoque cualitativo- mixto es el más apropiado para la visión y análisis en el campo interdisciplinar, transdisciplinar y en muchas ocasiones contra-disciplinar. 
En el Municipio Inteligente, el enfoque cualitativo se selecciona cuando el propósito es examinar la forma en que los actores perciben y experimentan los fenómenos que los rodean, profundizando en sus puntos de vista, interpretaciones y significados. Es un proceso inductivo, recurrente, que analiza múltiples realidades subjetivas. Por tanto, no tiene secuencia lineal. La bondad del enfoque al investigar en el municipio se encuentra en la profundidad de significados, amplitud, riqueza interpretativa y contextualiza el fenómeno. La investigación se enfoca en comprender los fenómenos de carácter multidimensional, explorándolos desde la perspectiva de los participantes en un ambiente natural y en relación con su contexto.

\subsubsection{Metodología para la investigación. Metodología de la Investigación Acción Participativa}

La investigación-acción o tema generador en la consecución de Municipios Inteligentes, tiene como fundamento la libertad y la necesidad del dialogo que significa la condición de posibilidad inquebrantable entre acción y reflexión. En este propósito, la investigación acción participativa la llevan a cabo las y los participantes en situaciones sociales para mejorar sus propias prácticas, el entendimiento de las mismas y las situaciones dentro de las cuales tienen lugar.

Cabe decir que, que el método de investigación en la consecución de Municipios Inteligentes por un Desarrollo Local Sostenible es aquel que permite la interacción entre investigador y actores del contexto, que también son intérpretes de su realidad; el contexto es la clave para comprender los significados de los fenómenos (contextual) y el sentido de la existencia (valorativo). Sin interacción no hay comprensión ni innovación relevante, y sin compromiso colectivo no hay capacidad para superar problemas complejos en la consecución de municipios inteligentes. La interpretación y transformación de la realidad depende del diálogo de "saberes", entre el conocimiento científico y otros "conocimientos tácitos" de los actores locales. Una ciencia de la sociedad, que no tiene intermediario porque es interactiva: ciencia con conciencia.

\subsubsection{Teoría - enfoque del desarrollo. Teoría del Desarrollo Humano}

En relación con esto último, se señala, que en la consecución de Municipios Inteligentes por un Desarrollo Sostenible es imprescindible, urgente y necesario, asumir la teoría del desarrollo humano como sustento teórico metodológico de dicho modelo. La asunción de dicha teoría no está dada a que rechace la visión anterior centrada en la producción de bienes, servicios o resultados, sino que, al referirse al desarrollo, no se trata del desarrollo de bienes o resultados, sino de resaltar la importancia del talento humano. Significa entonces, que se sustituye por una visión multidimensional, inter y transdisciplinaria centrada en la ampliación de las capacidades de las personas para lograr una gestión eficiente de los bienes, servicios y resultados, de manera que satisfagan las necesidades de las personas para su bienestar y prosperidad.

\subsubsection{Paradigma del desarrollo. Paradigma de desarrollo de la multiplicidad o pluralista}

El modelo participativo del desarrollo local sostenible municipal es la expresión concreta del paradigma de la multiplicidad desde la comunicación. De acuerdo con esta perspectiva se alcanza una valorización de los conocimientos locales de los actores en el municipio, se generarán redes locales que permiten a la población acceder a la información, pero que a la vez los transforma en productores de conocimiento. En este sentido, se percibe a las personas no 
sólo como receptores de información, sino que sugiere que todos son emisores y receptores. La comunicación se produce de forma horizontal, siendo cada sujeto un receptor y emisor. Desde este punto de vista, es en el acto creativo y combinatorio de conocimientos donde se traza el camino hacia el desarrollo.

\subsubsection{Paradigma emergente en cambio de época. El constructivismo - comprender para transformar}

El supuesto fundamental del constructivismo para el desarrollo local sostenible municipal es que los seres humanos construyen, a través de la experiencia, su propio conocimiento y no simplemente reciben la información procesada para comprenderla y usarla de inmediato; es necesario construir modelos mentales que puedan ser cambiados, amplificados, reconstruidos y acomodarlos a nuevas situaciones.

Estas premisas condicionan cada una de las dimensiones -ontológica, epistemológica, metodológica y axiológica- asociadas al esfuerzo de generación, acceso y apropiación de conocimiento correspondiente al paradigma constructivista en la consecución de Municipios Inteligentes por un Desarrollo Local Sostenible.

Dimensión ontológica (sobre la naturaleza de la realidad) ¿Qué es un Municipio Inteligente en la construcción del Desarrollo Local Sostenible? Dimensión epistemológica (sobre la naturaleza del conocimiento y del proceso para su generación) ¿Qué es relevante conocer en un Municipio Inteligente en la construcción del Desarrollo Local Sostenible? Dimensión metodológica (sobre el método y la naturaleza del indagar) ¿Cómo conocer lo que es relevante conocer en un Municipio Inteligente en la construcción del Desarrollo Local Sostenible? Dimensión axiológica (sobre los valores éticos y estéticos y la naturaleza de la acción) ¿Qué valores éticos y estéticos deben ser considerados en la interacción social para conocer lo que es relevante conocer en un Municipio Inteligente en la construcción del Desarrollo Local Sostenible?

\subsubsection{Visión de cambio contextual. Modo Contextual - constructivista: realidad socialmente construida, comprensión de significados en el contexto sentido de la existencia en el contexto}

De los anteriores planteamientos se deduce, que en la consecución de Municipios Inteligentes por un Desarrollo Local Sostenible es necesario una visión contextual desde la triple hélice para el desarrollo donde se tenga presente que:

En el contextualismo no existe una, sino múltiples realidades, todas dependientes de las diferentes percepciones de los diferentes grupos de actores sociales - universidad, gobierno, comunidad. De esta forma, se asume que si la realidad es socialmente construida puede ser socialmente transformada por nuevas percepciones, decisiones y acciones.

Cabe agregar que, en las investigaciones, el modo contextual asume el holismo, donde es relevante comprender principalmente los procesos de interacción a través de los cuales los diferentes grupos de actores sociales, económicos, políticos e institucionales construyen sus diferentes percepciones de la realidad municipal.

En el municipio, el modo contextual asume que sin interacción no hay comprensión. Con eso, la generación de comprensión incluye el entendimiento de ciertos procesos y relaciones que ocurren en el contexto de la investigación que sólo el conocimiento tácito de los actores 
locales puede complementar el esfuerzo de investigación.

En este sentido, en la consecución de municipios inteligentes la investigación debe ser interactiva para aumentar el grado de validez de sus resultados y la relevancia de sus impactos, porque los actores sociales del contexto de la investigación son también intérpretes activos y permanentes de su realidad; si ellos no participan activamente de la investigación, difícilmente encontrarán motivos relevantes para comprometerse con las consecuencias de sus resultados.

El modo contextual asume el activismo frente a la necesidad de la interacción humana para crear consenso sobre el municipio, el conocimiento para interpretar y accionar en el municipio, y los valores, intereses y compromisos que deben prevalecer en el proceso de transformación del municipio.

\subsubsection{Modos de innovación - en interacción con el contexto}

En Municipios Inteligentes por un Desarrollo Local la unidad ciencia e innovación son imprescindible para su consecución y la relación teoría y práctica para comprender y transformar el contexto municipal. Por, sobre todo, la innovación para el desarrollo sostenible municipal emerge de la interacción; las innovaciones relevantes emergen de procesos de interacción social, con la participación de los que de ellas necesitan. Las "organizaciones de innovación" actúan interactivamente en su contexto relevante, sin separar investigación-transferencia-adopción, sino integrando todos esos procesos en uno solo, de construcción colectiva.

\subsubsection{Enfoques: de la complejidad - holístico - integración - relaciones - significados cambiantes}

De esta forma se asume el holismo en las investigaciones para el desarrollo sostenible municipal, donde es relevante comprender principalmente los procesos de interacción a través de los cuales los diferentes grupos de actores sociales, económicos, políticos, sociales e institucionales construyen sus diferentes percepciones de la realidad del contexto actuación. Esta forma sistémica asume que el conocimiento de las partes es necesario pero insuficiente para comprender la dinámica del todo, lo que exige entender las relaciones entre las partes, entre éstas y el todo, entre el todo y sus partes y entre el todo y otros sistemas de relaciones que constituyen, a su vez, su contexto relevante.

El modo contextual construye síntesis sobre la dinámica del todo, los problemas del desarrollo son típicamente multidimensionales, interdisciplinarios e intersectoriales el entendimiento de las ramificaciones complejas de la sostenibilidad de municipios inteligentes requiere la integración de información de un rango amplio de disciplinas. La tarea vital es integrar las dimensiones críticas del debate, para recoger o producir la información en lo científico, socio-económico-culturalambiental-político y filosófico que orienten la generación de políticas prácticas y efectivas.

\section{CONCLUSIONES}

Las pautas de los fundamentos teóricos y metodológicos que sustentan el Municipio Inteligente por un Desarrollo Local Sostenible desde la gestión del conocimiento, negociada y consensuada por los actores sociales del contexto municipal se hace necesaria desde el paradigma de investigación socio-crítico, bajo un enfoque investigativo cualitativo - mixto, sobre la base 
de la metodología de la investigación - acción - participativa, con un sustento en la teoría del desarrollo con enfoque humano y el paradigma emergente en cambio de época constructivista, en la misma forma es necesario, los principios incluyente, humano, sostenible, participativo, ético, equitativo, social, autogestionable e integral, esenciales a tener presente en la construcción del municipio que se quiere para el futuro.

La consecución de Municipios Inteligentes por un Desarrollo Local Sostenible como proceso de gestión social del conocimiento, de carácter multidimensional, contextual, participativo, de interacción social, con enfoque de la complejidad desde análisis interdisciplinarios y transdicisplinario es posible con la integración de la triple hélice social para el desarrollo cuyas hélices en este caso especifican las funciones de la universidad - ciencia e innovación-, el gobierno y la comunidad en la construcción y concertación de los fundamentos teóricos metodológicos para el municipio que se quiere construir.

\section{REFERENCIAS}

ALBUQUERQUE, F.; COSTAMAGNA, C.; FERRARO, J. Desarrollo local, descentralización y democracia: ideas para un cambio. San Martín: UNSAM, 2008.

ARBONÍES, A. Conocimiento para innovar: cómo evitar la miopía en la gestión de conocimiento. 2. ed. Madrid: Madrid S. A., 2007.

AROCENA, R.; SUTZ, J. Knowledge, innovation and learning: systems and policies in the north and in the south. In: CASSIOLATO, J. E.; LASTRES, H. M.; MACIEL, M. Systems of innovation and development. Montevideo: Universidad Montevideo, 2003.

AROCENA, R.; SUTZ, J. La universidad en las políticas de conocimiento para el desarrollo inclusivo. Cuestiones de Sociología, Ciudad México, n. 12, p. 1-18, 2015. Disponible en: https://www.cuestionessociologia.fahce. unlp.edu.ar/article/view/CSn12a02/6702. Acceso en: 25 sep. 2017.

BAQUERO, M. I., RENDÓN, J. A. Desarrollo humano local: la alternatividad para el buen vivir. Revista de la Universidad de la Salle, Bogotá, v. 10, n. 54, 20 p. 2014.

BECERRA, G. El "constructivismo operativo" de Luhman: una caracterización relacional con el constructivismo de inspiración piagetiana y el constructivismo radical. Revista Enfoques, Buenos Aires, v. 26, n. 2, p. 29-54, 2014.

BERTONI, R; CASTELNOVO, C.; CUELLO, A.; FLEITAS, S.; PERA, S.; RODRÍGUEZ, J.; RUMEAU D. Construcción y análisis de problemas del desarrollo: ¿qué es el Desarrollo? ¿Cómo se produce? ¿Qué se puede hacer para promoverlo? Montevideo: Universidad de la República, 2011.

BOUSKELA, M.; CASSEB, M.; BASSI, S.; DE LUCA, C.; FACCHINA, M. La ruta hacia las Smart Cities: migrando de una gestión tradicional a la ciudad inteligente. [s.I.]: Banco Interamericano de Desarrollo, 2016.

BRITO, A.; ARTIGAS, E; MARTíNEZ, R. La universidad en la consecución de municipios inteligentes por un desarrollo local sostenible. Revista DELOS, Málaga, v. 10, n. 30, 26 p, 2017. Disponible en: https://www. eumed.net/rev/delos/30/universidad-desarrollo-sostenible.html. Acceso en: 25 sep. 2017.

CARVAJAL, A. Desarrollo local - manual básico para agentes de desarrollo local y otros actores. Málaga: Eumed, 2011.

CANTO, P., COSTAMAGNA, P., EIZAGIRRE, A., Y LARREA, M. Los retos de la cogeneración en la búsqueda 
del impacto social de la universidad: un caso de construcción de un espacio dialógico a través de la investigación acción. European Public \& Social Innovation, Bilbao, v. 3, n. 1, p. 46-67, 2018.

CASTRO DÍAZ-BALART, F. (Ed.). Ciencia, tecnología e innovación: desafíos e incertidumbres para el Sur. La Habana: Ediciones Plaza, 2006.

CASTRO, E., SUTZ, J. Universidad, conocimiento e innovación. In: ALBORNOZ, M.; LÓPEZ, J. A. (Ed.). Ciencia, tecnología y universidad en Iberoamérica. Buenos Aires, AR: OEI, 2010. p. 2-119.

CHUA, A. The dark side of success full knowledge management initiatives. Journal of Knowledge Management, Nanyang, v. 13, n. 4, p. 32-40, 2009.

COSTAMAGNA, P.; SPINELLI, E.; PÉREZ, R. Elementos estratégicos de un enfoque pedagógico para el desarrollo territorial. Bilbao: ConectaDEL, 2013.

COSTAMAGNA, P; PÉREZ, S. Enfoque, estrategias e información para el Desarrollo Territorial. Los aprendizajes desde ConectaDEL. Programa Regional de Formación para el Desarrollo Local con Inclusión Social en América Latina y El Caribe. Buenos Aires, 2015

COSTAMAGNA, P.; LARREA, M. Actores facilitadores del desarrollo territorial - una aproximación desde la construcción social. Bilbao: Orkestra, 2017.

DE SOUZA, J. La crisis global de la innovación para el desarrollo: del positivismo al constructivismo para construir modos de vida localmente sostenibles. Revista Cubana de Ciencia Agrícola, San José de las Lajas, v. 48, n. 1, p. 11-15, 2014.

DE SOUZA, J. Otro paradigma para el desarrollo humano sustentable: ascenso y declinación de la idea de desarrollo. Revista Textual, Campina Grande, v. 28, n. 55, p. 9-25, 2010.

DE SOUZA, J. La geopolítica del conocimiento y la gestión de procesos de innovación en la época histórica emergente. Campina Grande: ISNAR, 2008.

DE SOUZA, J.; CHEAZ, J. Generación de conocimiento y construcción de teoría en proyectos de desarrollo de capacidad institucional. San José: Editorial ISNAR, 2003.

DI-DOMÉNICO, A. El conocimiento como recurso, una ventaja competitiva. Mar del Plata, AR: Biblioteca Central Nacional de Mar del Plata, 2008. Disponible en: Acceso en: 15 mar. 2014.

DÍAZ-CANEL, M. Conferencia magistral durante el 8vo. Congreso Internacional de Educación Superior, "Universidad 2012", realizado en el teatro "Karl Marx", de La Habana, el 13 de febrero de 2012.

DUBOIS, A. 2014 Marco teórico y metodológico del desarrollo humano local: Instituto sobre Estudios de Desarrollo y Cooperación Internacional. Universidad País Vasco. 2014.

GARCÉS, R. La gestión del conocimiento como herramienta para el desarrollo local comunitario. Revista Gestión del Conocimiento, Santa Clara, v. 4, n. 3, 2013.

GARCÍA, R. Interdisciplinariedad y sistemas complejos. Revista Latinoamérica de Metodología de las Ciencias Sociales, La Plata, v. 1, n. 1, 2011.

HERRERA, R.; GUTIÉRREZ, J. M. Conocimiento, innovación y conocimiento. San José, Costa Rica: Gráfica del Este, 2011. 292 p.

KARLSEN, J.; LARREA, M. The contribution of action research to policy learning. International Journal of 
Action Research, Buenos Aires, v. 10, n. 2, p. 129-55, 2014.

KARLSEN, J.; LARREA, M. Desarrollo territorial e investigación acción: innovación a través del diálogo. Bilbao: Fundación Deusto, 2015.

LAGUNA, G.; MARCELÍN, G. Complejidad y sistemas complejos: un acercamiento multidimensional. México: Coplt-arXives y EditoraC3, 2016.

LARREA, M. A. La Gestión del Conocimiento y la Universidad del Futuro. Revista FACES, Buenos Aires, v. 17, n. 1, p. 21-34, 2016.

MUIICA, M.; MARÍN F.; LOVERA, M. I. Municipio innovador, un modelo para el desarrollo local sostenible. Multiciencia, Zulia, v. 8, n. 24, p. 28-36, 2009.

LUENGO, M.; OBESO, M. El efecto de la triple hélice en los resultados de innovación. Revista de Administración de Empresas, Sao Paulo, v. 53, n. 4, p. 388-99, 2013.

NINO, A., VÉLEZ, J. H.; LARA, E. Generación de capacidades y participación en el desarrollo local: una Guía de orientación para trabajo comunitario. San Isidro: [s.n.], 2010.

NÚÑEZ, J. Educación superior y desarrollo local: la agenda emergente y sus demandas conceptuales. Boletín GUCID, La Habana, año 1, n. 1, p. 6-14, 2010.

OJEDA, R. Hoja de ruta hacia un municipio inteligente por un desarrollo agrario y rural sostenible. In: TALLER INTERNACIONAL "UNIVERSIDAD CIENCIA Y TECNOLOGÍA", 7., CONGRESO INTERNACIONAL DE EDUCACIÓN SUPERIOR. 12/02/2012, La Habana. Anales [...]. La Habana: Palacio de las Convenciones, 2012.

OJEDA, R.; RAMOS, A. E. Municipio inteligente por un desarrollo agrario y rural sostenible. Mayabeque: Biblioteca Virtual para el Desarrollo del CEGED-UNAH, 2013.

PASSAILLAIGUE, R.; ESTRADA, V. La gestión del conocimiento y el aprendizaje organizacional en instituciones de educación superior. Revista Internacional de Gestión del Conocimiento y la Tecnología, Ecuador, v. 4, n. 2, p. 35-43, 2016.

PINEDA, K.; MORALES, M.; ORTIZ, M. Modelos y mecanismos de interacción universidad-empresa-Estado: retos para las universidades colombianas. Equidad y Desarrollo, Bogotá, v. 19, n. 15, p. 41-67, 2012.

PROGRAMA DE NACIONES UNIDAS PARA EL DESARROLLO [PNUD]. Informe sobre Desarrollo Humano. Nueva York: PNUD, 2011. Disponible en: http://hdr.undp.org/es/informes/mundial/idh 2011/. Acceso en: 14 oct. 2014

RODRÍGUEZ, A. E. R; FERNÁNDEZ, D. B; PÉREZ, E. A. Desarrollo de capacidades para el desarrollo local en cambio de época. Interações, Campo Grande, MS, v. 16, n. 2, p. 12, 2015. Disponible en: https://www. interacoes.ucdb.br/interacoes/article/view/73. Acceso en: 26 dic. 2015.

RAMOS, A.; BRITO, A.; ARTIGAS, E.; BÁEZ, D.; MARTínEZ, R. Pensar y actuar de manera diferente para la prosperidad y sostenibilidad. Centro de Estudios Desarrollo Agrario y Rural. San José de las Lajas: UNAH, 2016.

RODRÍGUEZ, A. E. R; MONTERO, A. B.; PÉREZ, E. A.; GARCÍA, R. M La Triple hélice social para el desarrollo desde la gestión del conocimiento. Delos - Desarrollo Local Sostenible, Málaga, v. 11, n. 33, p. 22, 2018. https://www.eumed.net/rev/delos/33/desarrollo-gestion-conocimiento.html.

SOLER, Y. Teorías sobre los sistemas complejos. Revista Administración y Desarrollo, Bogotá, v. 47, n. 2, 
p. 52-69, 2017.

SOUZA, C. L.; AWAD, J. Cidades sustentáveis, cidades inteligentes - desenvolvimento sustentável planeta urbano. Porto Alegre: Bookman, 2012.

VILLATORO, P. The value added of including income in a multidimensional poverty index: the case of Latin America. [Mimeo]. 2016.

\section{Sobre los autores:}

Alejandro Emilio Ramos Rodríguez: Doctor en Ciencias de la Cultura Física en la Universidad de en Ciencias de la Cultura Física. Profesor titular. Coordinador de la Línea de Investigación de Teorías y Enfoques del Desarrollo del Centro de Estudios para la Gestión del Desarrollo. Coordinador del Programa de Maestría de Desarrollo Agrario y Rural Sostenible. Coordinador de la Línea de investigación Desarrollo Local Sostenible de la Universidad Agraria de la Habana. Miembro del Tribunal Nacional de Grado Científico de Cultura Física. Miembro de la Comisión Nacional de posgrado de la República de Cuba. E-mail: alerr1954@gmail.com, Orcid: http://orcid.org/0000-0001-7498-2420

Elaine Artigas Pérez: Master en Ciencia de Desarrollo Agrario y Rural Sostenible en la Universidad Agraria de la Habana Graduación en Estudios Socioculturales. Profesora asistente Facultad de Ciencias Sociales y Humanísticas. Profesora e investigadora del Centro de Estudios para la Gestión dl Desarrollo (Ceged). Grupo de Investigación Teorías y Enfoque del Desarrollo del Ceged. E-mail: elaine_artigas@unah.edu.cu, Orcid: http://orcid.org/0000-0002-4905-7265

Aimara Brito Montero: Master en Desarrollo Territorial en la Universidad de la Habana. Graduación en Pedagogía en la especialidad de Geografía. Profesora e investigadora del Centro de Estudios para la Gestión dl Desarrollo (Ceged). Profesora auxiliar. Grupo de Investigación Teorías y Enfoque del Desarrollo del Ceged. E-mail: aymarabm@unah.edu.cu, Orcid: http://orcid.org/0000-0002-0239-0909 